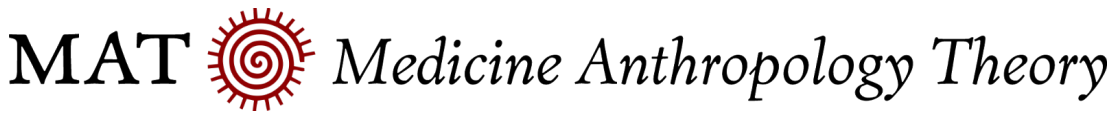

REVIEW ESSAYS

\section{Comparative explorations Of human-poultry relationships, pandemic preparedness and the search for viral epicentres}

\author{
Rebekah Grace Thompson
}

Received: 15 November 2020; Accepted: 18 January 2021; Published: 23 April 2021

\section{Abstract}

In this book review, I compare three timely ethnographies that critically explore the topics of human-poultry relationships, avian influenza, and global health. I start the review by considering how the three authors, each located in a different context, approach these topics by drawing upon distinct methodological and theoretical frameworks. I then show how these approaches shape the way in which the authors discuss three separate concepts: preparedness, experiments, and viruses. I conclude that, whether read independently or together, these books illustrate the power of ethnographic research in exposing the distinctive ways that people envisage the relationships between human and non-human lives and the implications of such distinctions for disease control.

\section{Keywords}

Poultry, Viruses, Avian influenza, Human-animal relationships, Pandemics. 


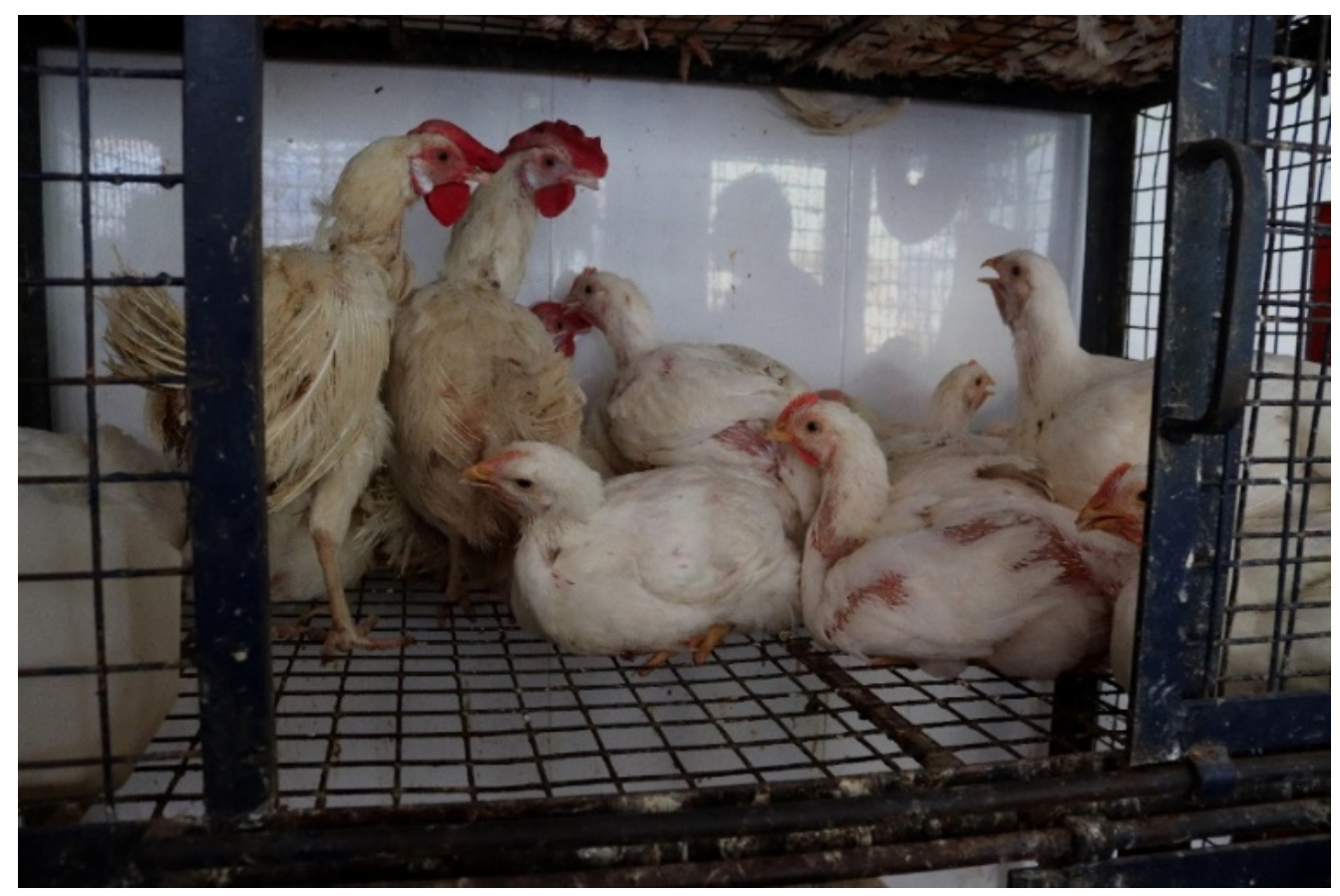

1. The transportation of broiler chickens. Bengaluru, India. Photo by the author, 2019. I took all the pictures included in this review while conducting ethnographic research for a multidisciplinary project on antibiotic use along the broiler supply chain in three states in southern India.

\section{Introduction}

Despite significant overlaps, my research differs from the books reviewed in this essay in that its focus is not on viruses with pandemic potential, but rather the development and spread of antibiotic-resistant bacteria. This focus on bacteria rather than viruses comes in response to what scientists have dubbed the 'silent pandemic' (Ahmad and Khan 2019); that is, the growing global health concerns around the impact of antibiotic resistance on human and animal health. Despite this difference in the microorganism being studied, these three books have enriched my current research in a number of significant ways. In particular, they have opened up new ways of understanding how the intensification of poultry production systems is reconfiguring human and non-human lives, and have encouraged me to rethink the ways in which different people, organisations, and governments anticipate and respond to potential pandemic threats.

The COVID-19 pandemic has prompted many questions about how the world can prepare for and respond to emerging disease threats. COVID-19, which is caused by a coronavirus (SARS-CoV-2), is a highly pathogenic, transmissible virus that scientists speculate originated from an animal source (Mackenzie and Smith 2020). COVID-19 is genetically similar to another coronavirus, the severe acute 
respiratory syndrome (SARS) virus (Kaur and Gupta 2020), which first emerged in 2002 and spread from China to a number of countries around the world. As the three books reviewed explain, it was in the aftermath of the SARS outbreak that governments and global health organisations rapidly focused their attention and resources on preventing the next pandemic. This, in turn, led to an increased focus on influenza viruses and one virus in particular known as type A (H5N1).

H5N1 is a highly pathogenic avian influenza virus. It is highly contagious among birds and can also be transmitted to humans, causing severe symptoms and, in many cases, death. As such, since 1997, when the first human case of H5N1 was isolated from a child in Hong Kong, vast numbers of people and resources have been mobilised in order to anticipate and prevent its spread. As the authors all illustrate, the threat of avian influenza (also known as bird flu) is situated in a context in which global poultry numbers are and have been rapidly rising. As poultry numbers grow, the production process intensifies, bringing together people, birds, and microbes in new and transformative ways.

As health experts strive in parallel to contain the associated disease risks of growing poultry numbers, anthropologists are beginning to ask a number of pertinent questions. How, for example, do farmers care for and value their poultry in different contexts? How do an increase in and intensification of poultry farming and poultry consumption impact the emergence and spread of diseases? And how are ensuing preparedness and prevention techniques transforming our relationships with birds and viruses? These are some of the questions asked by Frédéric Keck, Lyle Fearnley, and Natalie Porter in their three incredibly timely books. The authors, located in diverse geographic locations, approach these questions by engaging with distinct methodological and theoretical frameworks.

In Avian Reservoirs, Keck explores the contrasting strategies by which different people respond to emerging avian influenza threats in Hong Kong, Singapore, and Taiwan. Keck, who is based in France, begins by defining 'avian reservoirs' not as problematic sites of interspecies mingling, but rather as 'space[s] where human and non-human animals are connected by invisible entities called "microbes" that can be captured, classified, and mapped' (Keck 2020, 4). Throughout the chapters of his book, Keck makes a distinction between the concepts of preparedness and prevention through advancing a style he describes as 'philosophicalanthropological (or fieldwork in philosophy)' (idem, 6). In accordance with and by using concepts from the anthropology of hunter-gatherers, Keck follows microbiologists and ornithologists to explore the 'cynegetic' or hunting techniques of preparedness. He then contrasts this approach with the pastoral techniques of prevention as carried out by public health professionals. In the three ethnographic chapters of his book, Keck furthers this distinction by linking three strategies for 
dealing with pandemic threats with the three separate Asian territories: sentinels with Hong Kong, simulations with Singapore, and stockpiling with Taiwan. By doing so, Keck shows how the three Asian territories have positioned themselves against China in response to emerging disease threats. Thus, by theorising the concepts of preparedness and prevention not just as techniques but as tools, Keck opens up new ways of thinking about public health, scientific practices, and humananimal relationships.

Keck explores how Hong Kong, Taiwan, and Singapore have used avian influenza as a way of expressing the issues they have with mainland China as an emerging source of geopolitical power and potential disease threats. Yet it is in Lyle Fearnley's book, Virulent Zones, that the reader journeys directly into southern China-the hypothesised 'epicentre' of the next influenza pandemic. As Fearnley states, China has been marked by scientists as a 'double locus of planetary danger' (Fearnley 2020, 157): first as a hot spot of emerging viruses and second as a weak link in global preparedness. In Virulent Zones, Fearnley, an anthropologist of science and medicine trained in the US and currently based in Singapore, leaves the laboratory and journeys with global health scientists as they travel to the duck farms around China's largest body of freshwater, Poyang Lake. By following virologists, veterinarians, and wild bird trackers as they meet duck farmers in southern China, Fearnley contends that there is a need to look beyond the scale of the avian influenza virus and towards wider zones of virulence (idem, 10). To guide the reader into the hypothetical epicentre, Fearnley's book is divided into three sections: 'ecology', 'landscape', and 'territory'. Defining these sections as layers, Fearnley explains how, when scientists moved into southern China, they found no linear trajectory that could lead them to the discovery of a virus but rather a series of displacements that generated new questions around the causes and contexts of disease. Thus, by following scientists and their experimental systems into China, Fearnley shows the types of epistemological and normative displacements that occur when scientists are faced with ducks and people on farms rather than viruses under the microscope.

Zoonotic diseases-that is, those diseases transmitted between humans and animals-are changing global health by bringing together experts working on humans, animals, and the environment under a single umbrella of 'One Health'. While all of the authors whose books I review here discuss the emergence and consequences of a One Health approach, it is Natalie Porter's ethnographic details that most explicitly demonstrate the implications and failings of One Health in practice. In her book Viral Economies, US-based medical anthropologist Porter explores bird flu control programmes as they are rolled out in Vietnam-a context in which H5N1 outbreaks have resulted in the slaughter of millions of birds and the deaths of over 100 people (Porter 2019, 2). Throughout her book, Porter follows 
transnational scientists, NGO workers, state veterinarians, and poultry farmers to show how pandemic interventions are 'made and remade on the ground, in state policy arenas and in the everyday labor of livestock care' (idem, 7). In line with her findings, Porter reasons that One Health governance and bird flu interventions are best understood as a series of experiments that govern relationships between species. By bringing multispecies exchange relationships to the forefront of her discussion, Porter demonstrates how important it is for global public health to recognise and acknowledge that we live in a more-than-human world. If we fail to recognise this, she suggests, global health interventions will continue to generate and reinforce systems in which some lives have more value than others.

In what follows, I explore how the authors discuss three concepts: preparedness, experiments, and viruses. By doing so, I contend that whether read independently or together, these books illustrate the power of ethnographic research in exposing the distinctive ways that different people envisage the relationships between human and non-human lives and the implications of such distinctions for disease control in different contexts.

\section{Preparedness}

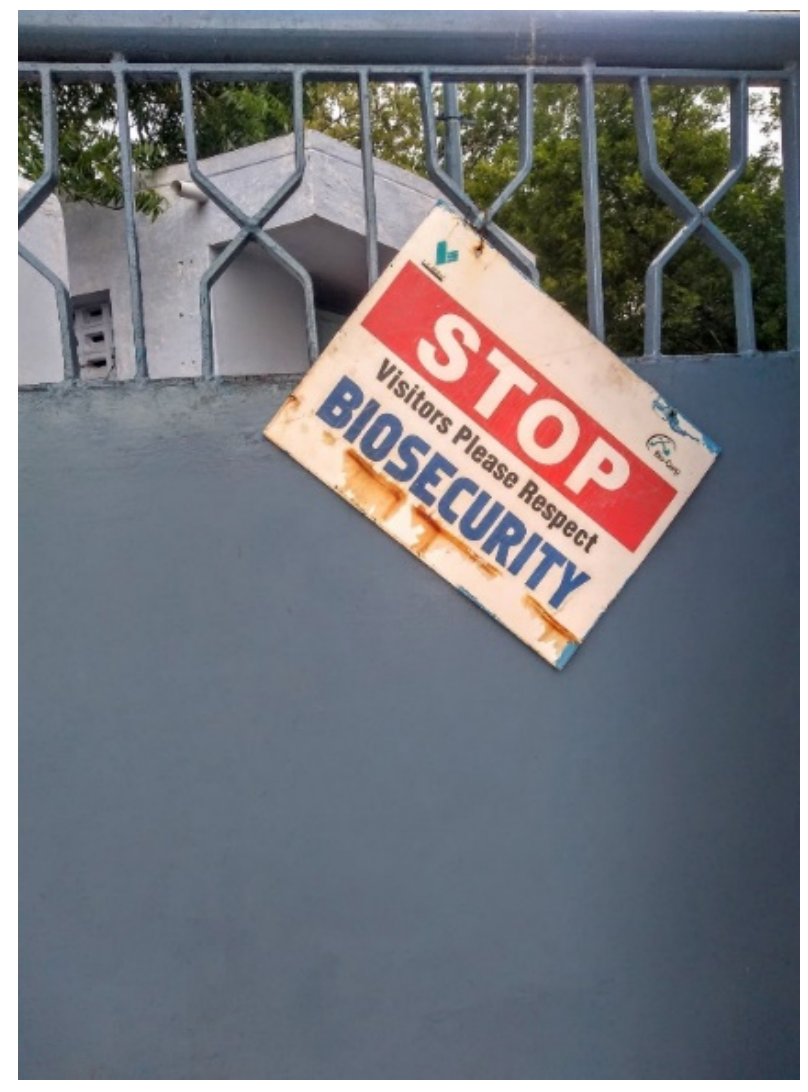

2. A biosecurity sign outside a hatchery in Namakkal, India. Photo by the author, 2019. 
Each of the three books offers new insights regarding pandemic preparedness, a concept that has already generated rich discussion among social anthropologists (e.g., Caduff 2014; Lakoff 2017; Lynteris and Poleykett 2018). As this existing literature demonstrates, preparing for a future pandemic is not explicitly about prevention, but rather the development of techniques and technologies that build resistance and act as early warning systems.

In his book, Keck illustrates how 'techniques to prepare for influenza pandemics have transformed our relations to birds' (Keck 2020, 2). For Keck, one technique of preparedness is the hunting of signs from sentinels, which in turn allows humans to anticipate future disease threats. He shows how, in his field sites, microbiologists and ornithologists, like hunters, come to know their prey (in this case birds and viruses) by the signs or signals that they transmit. This approach, Keck argues, contrasts with the practices of epidemiologists and public health practitioners, who, rather than observe their environments through the eyes of their prey, use techniques such as culling in the name of prevention. In his fourth chapter, Keck charts how sentinel posts have been established at the level of the cell, farm, territory, and the migratory flyway. For instance, at the level of the farm, Keck shows how virologists strategically place live birds to detect early signs of disease. Developing this notion further, he argues that Hong Kong, like a sentinel chicken in a cage, has come to act as a global sentinel post, a place from which to apply preparedness techniques and monitor emerging global disease threats. While Keck's discussion of preparedness is intensely theoretical, Fearnley and Porter both clearly show what happens when preparedness techniques and associated disease control activities (such as the implementation of biosecurity measures and vaccination regimes) meet the everyday lives of poultry farmers in China and Vietnam.

In their books, both Porter and Fearnley show how agricultural development has become synonymous with disease management. This semantic merging is in line with an assumption that the cultivation of disease-free poultry coincides with the commercialisation of poultry systems. Yet both authors show how this is not materialising on the ground. In the third chapter of his book, Fearnley draws on fieldwork with poultry farmers around Poyang Lake to show how the biosecurity protocols proposed by the Food and Agriculture Organization (FAO) to control viruses 'at source' (Fearnley 2020, 67) intersected with farmers' everyday practices in southern China. In accordance, Fearnley discusses the various factors that inform the decisions of many farmers to allow their ducks to free-roam, a practice deemed a threat to biosecurity by the FAO. By doing so, Fearnley illustrates how, for farmers, free-roaming ducks reduced the uncertainty of investing household wealth into a risky animal body. As a result, scientists' anticipatory discourse, which identified Poyang Lake as a pandemic epicentre, 
fuelled farmers' uncertainties around duck rearing. This, in turn, increased farmers' reliance on free-roaming practices in order to mitigate potential disease risks. Thus, Fearnley highlights how FAO biosecurity interventions, enacted in the name of pandemic preparedness, failed to acknowledge the ways in which farmers managed different poultry-related uncertainties around Poyang Lake.

In her book, Porter does not explicitly focus on the topic of preparedness but rather engages a broader multispecies perspective (Haraway 2008; Kirksey and Helmreich 2010) in order to push public health beyond the human. By doing so, she illustrates that many bird flu interventions do not 'properly account for the conditions under which farmers and fowl actually live' (Porter 2019, 14). In her account of vaccinating birds for H5N1, Porter demonstrates how farmers perceived proximity to their birds to be immunising rather than harmful to human health. Thus, farmers vaccinated their birds primarily to protect poultry health and their livelihoods. Moreover, Porter shows how, in a context in which H5N1 in domestic birds is endemic and vaccination is a task traditionally carried out by farmers, veterinary expertise has diminished value. Farmers did not trust veterinarians to appropriately care for the health of their poultry and vaccinations did not work as a 'quick-fix' solution for viral control. Thus, Porter points out that, when livestock care is entangled in farmers' lives and livelihoods, recognising the ecological and economic conditions in which diseases arise is just as important as attempts to prevent viral outbreaks through vaccination programmes.

\section{Experiments}

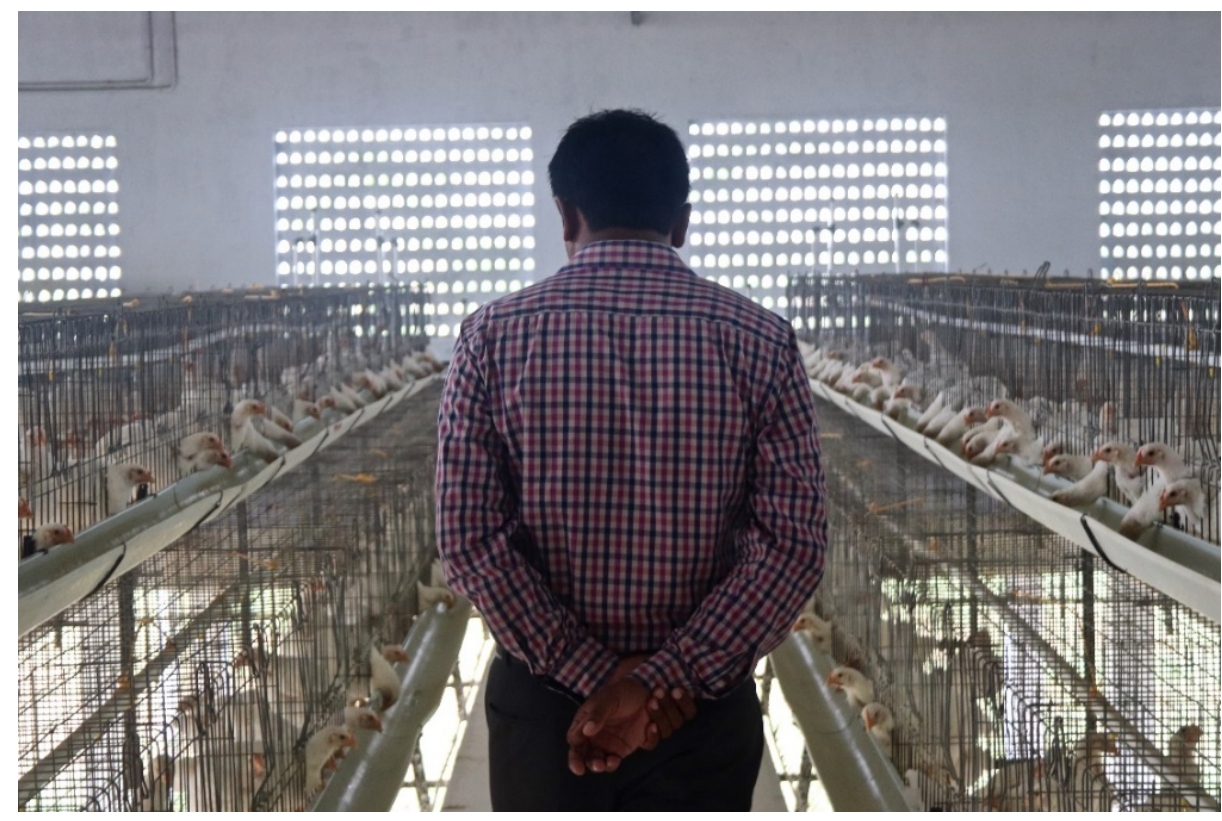

3. A poultry veterinarian observing broiler breeders on a parent farm in Namakkal, India. Photo by author, 2019. 
Anthropologists and historians of science have long explored the links between the experiment, the laboratory, and the production of scientific knowledge (e.g., KnorrCetina 1995; Latour 1988; Rheinberger 1997). Building on this work, Fearnley pushes against the notion that all scientific knowledge has to be produced by experiments conducted in the laboratory. For example, in his fourth chapter, Fearnley explores the scientific hypothesis that contact between wild and domestic birds influences the emergence of avian influenza. In response, Fearnley documents the ways in which wild geese breeders around Poyang Lake engaged in a process whereby they cultivated wildness in birds without explicitly taming them. Wildness in this context was constructed around three main traits, the most significant of which was the birds' ability to fly (Fearnley 2020, 109). Poultry breeders were therefore reshuffling the 'material qualities of wildness and domesticity in their husbandry of swan geese' (idem, 98). Thus, when scientists observed farmers 'breeding wildness' (idem, 115), they were confronted with a different way of understanding the boundary between wild and domestic birds. As Fearnley contends, this reconceptualisation of a previously defined boundary based on the practices of poultry breeders in turn shifted the trajectory of scientists' experiments and the production of scientific knowledge.

Like Fearnley, Porter also discusses the concept of the experiment, the work of Rheinberger (1997), and the notion that experiments can take place beyond the sites traditionally associated with scientific practice. In accordance, Porter argues that experiments are best understood as 'exercises in valuing life, determining life chances, and fashioning ways of life' (Porter 2019, 21). To illustrate, in her first chapter Porter demonstrates how 'new life forms come into being alongside new forms of life on experimental, biosecure farms' (idem, 39). Porter subsequently shows how biosecurity measures were increasingly adopted by 'entrepreneurial farmers', with successful farmers commodifying their birds in order to gain returns on their investments. Consequently, adopting biosecurity measures required farmers to be willing to take risks and experiment with new and uncertain relationships with both poultry and people.

While Keck does not refer to experiments in the same way as Porter or Fearnley, he does discuss techniques of simulation and their objective 'to rehearse a disaster situation to better prepare for it, to do as if the catastrophe had already happened in order to mitigate its effects' (Keck 2020, 108). Simulations are shown to have much in common with what Porter describes as an experiment; they 'seek to address problems in the here and now in order to engender something different down the line' (Porter 2019, 21). In accordance, Keck asks what it means to imagine future pandemics 'by building scenarios involving humans, animals, and artifacts' (Keck 2020, 109). Keck draws on examples of two types of simulation for disaster management: desktop and real-ground drills. In accordance, he shows 
how microbiologists, public health officials, and birdwatchers conduct different types of simulations in order to speculate on the different ways in which viral pandemics could be managed. By doing so, Keck argues that simulations should not be conceptualised simply as a pastoral technique that gathers people together in order to control a potential threat, but rather as a hunting technique. In line with this reasoning, simulations allow microbiologists and birdwatchers alike to adopt the perspectives of animals in order to imagine what could happen if a viral outbreak occurred.

\section{Viruses}

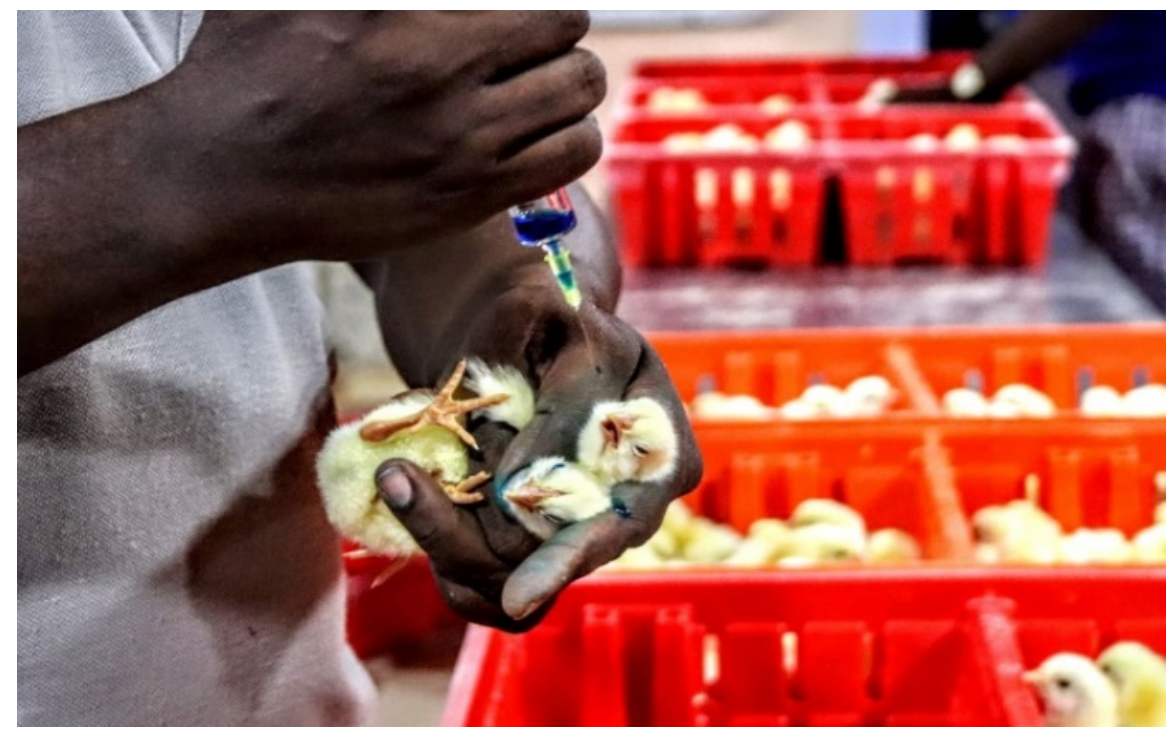

4. Vaccinating day-old broiler chicks at the hatchery, Namakkal, India. Photo by the author, 2019.

Each of the books I discuss demonstrates the fact that viruses are not just life forms, but also a type of information. This raises questions around the value of viruses, with the global sharing of viruses often at odds with the interests of individual nations. Thus, all of the authors highlight the ways in which viruses have become an asset that many nations strive to protect. To illustrate this 'biosovereignty' or 'viral sovereignty' (see Ong 2008), each author cites the example of the Indonesian government, which stopped sharing H5N1 samples in 2006. In this example, the Indonesian government accused global pharmaceutical companies of profiting from Indonesian flu samples while simultaneously neglecting the Indonesian people most at risk of avian influenza. Such virus ownership claims have since sparked new ways of thinking about the value of influenza viruses and the subsequent ways in which influenza samples are shared with global influenza surveillance systems. 
In his discussion on 'virus hunters', Keck charts the processes and techniques that microbiologists use in order to track, hunt, and store information on viruses and their mutations. This information, Keck argues, has been stored by the World Health Organization (WHO) since 1948 in the Centre for Influenza Research, a global 'museum' or collection of influenza viruses that enables microbiologists, global health organizations, and governments to anticipate and prepare for pandemics (Keck 2020, 47). Keck develops this further in his final chapter, in which he contrasts storing with the stockpiling of viruses. He argues that viruses are stored by public health authorities in order to preserve the past and to make vaccines that are subsequently stockpiled. Stockpiling, as a technique for preparedness, generates 'a new form of biovalue' (idem, 139) by simulating scarcity. Thus, whereas storage produces value as it allows for the accumulation of viral samples to be shared, stockpiling and the hoarding of viral strains produces value through the anticipation of future outbreaks.

Although viruses are valuable, not all viruses are valued in the same way. As Porter highlights in her final chapter, despite all the One Health agenda's emphasis on the risk of viruses 'spilling over', 'human and animal viruses live very different social lives' (Porter 2019, 168). As Porter emphasises, livestock animals are commodities, not citizens, and this has implications for the ways in which viruses are treated and valued. In her final chapter, Porter discusses how viral ownership claims create 'tethering' effects that anchor viruses to specific places and certain bodies (idem, 153). In response, Porter investigates how the WHO formed the Pandemic Influenza Preparedness (PIP) framework in order to ensure that nations directly benefited from sharing influenza samples. Yet, what Porter ultimately shows is that PIP did not account for animal viruses. Thus, it was only when animal viruses 'jumped' into human surveillance networks that these viruses could be claimed by nations and leveraged.

The value associated with viruses indicates why countries such as China are often framed by global health organisations as lacking transparency and being unwilling to share. Yet as Fearnley shows, the boundaries imagined to exist between China and the rest of the world are actually being navigated by global health professionals. In his fifth chapter, Fearnley provides an insight into the two strategies taken in order to access the hypothesised viral epicentre (Fearnley $2020,127)$. The first he labels 'affinity', which refers to the indirect strategies such as the cultivation of friendships or the attending of banquets. The second he labels 'stratification', which describes the supplanting of political space with ecological space. Thus Fearnley demonstrates that, unlike the 'virus hunters' who extract viral samples from the field and retreat back into the laboratory, global health professionals have to actively shape strategies in order to gain access to sites and viral information. 


\section{Conclusion}

Keck finishes his book by asserting that 'the ecology of infectious diseases has showed that viruses are not intentional entities aiming at killing humans, but signs that the equilibrium between species in an ecosystem has been disrupted' (Keck 2020 , 178). This is why, as Porter closes, we must reject any idea that there is only 'one' way of living with non-human species and instead 'imagine and enact more inclusive, more-than-human worlds' (Porter 2019, 188, author's emphasis). Perhaps the best way to do this is, as Fearnley concludes, by spotlighting cultural practices and ecological changes 'with as much care as viruses examined under the microscope' (Fearnley 2020, 212).

The three books reviewed all show the importance of using ethnographic methods to appreciate the contexts from which certain individuals, birds' bodies, places, and viruses come to be constructed as potential pandemic threats. The fact that these three books all link birds' bodies back to influenza viruses shows the power that certain microbes have in mobilising individuals, organisations, and governments in a way that others do not. Thus, as the world grapples with COVID-19, a pandemic caused by a coronavirus that is likely to have originated from an animal source, it becomes more important than ever for anthropologists to acknowledge the different ways in which people envisage human-non-human relationships and what this distinction can tell us about preparing for disease outbreaks in the future.

\section{Acknowledgements}

I would like to thank Bridget Bradley and the wider MAT reviews team for all their help in finalising this review essay. I would also like to thank the anonymous reviewer for their incredibly constructive comments on an earlier draft.

\section{About the author}

Rebekah Grace Thompson is a postdoctoral research associate in the Department of Geography at Royal Holloway, University of London. She works on humananimal relationships with a focus on livestock supply chains, zoonotic and epizootic diseases, and antimicrobial resistance. She is currently working on an interdisciplinary project named DARPI (Drivers for Antimicrobial Resistance in Poultry in India). 


\section{References}

Ahmad, Mohammad, and Asad U. Khan. 2019. 'Global Economic Impact of Antibiotic Resistance: A Review'. Joumal of Global Antimicrobial Resistance 19: 313-316. https://doi.org/10.1016/j.jgar.2019.05.024.

Caduff, Carlo. 2014. 'Pandemic Prophecy, or How to Have Faith in Reason'. Current Anthropology 55 (3): 296-315. https://doi.org/10.1086/676124.

Fearnley, Lyle. 2020. Virulent Zones: Animal Disease and Global Health at China's Pandemic Epicenter. Durham, NC: Duke University Press.

Haraway, Donna. 2008. When Species Meet. Minneapolis, MN: University of Minnesota Press.

Kaur, Simran Preet, and Vandana Gupta. 2020. 'COVID-19 Vaccine: A Comprehensive

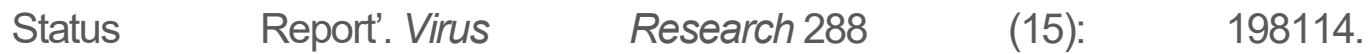
https://doi.org/10.1016/j.virusres.2020.198114.

Keck, Frédéric. 2020. Avian Reservoirs: Virus Hunters and Birdwatchers in Chinese Sentinel Posts. Durham, NC: Duke University Press.

Kirksey, Eben S., and Stefan Helmreich. 2010. 'The Emergence of Multispecies Ethnography'. Cultural Anthropology $25 \quad$ (4): 545-576. https://doi.org/10.1111/j.1548-1360.2010.01069.x.

Knorr-Cetina, Karen. 1995. 'Laboratory Studies: The Cultural Approach to the Study of Science'. Jasanoff, Sheila, Gerald E. Markle, James C. Peterson, and Trevor Pinch, eds. Handbook of Science and Technology Studies. London: Sage. 140167.

Lakoff, Andrew. 2017. Unprepared: Global Health in a Time of Emergency. Berkeley, CA: The University of Califomia Press.

Latour, Bruno. 1988. The Pasteurization of France. Cambridge, MA: Harvard University Press.

Lynteris, Christos and Branwyn Poleykett. 2018. 'The Anthropology of Epidemic Control: Technologies and Materialities'. Medical Anthropology 37 (6): 433-441. https://doi.org/10.1080/01459740.2018.1484740.

Mackenzie, John S. and David W. Smith, 2020. 'COVID-19: A Novel Zoonotic Disease Caused by a Coronavirus from China: What We Know and What We Don't'. Microbiology Australia 41 (1): 45-50. https://doi.org/10.1071/MA20013.

Ong, Aihwa. 2008. 'Scales of Exception: Experiments with Knowledge and Sheer Life in Tropical Southeast Asia'. Singapore Journal of Tropical Geography 29 (2): 117129. https://doi.org/10.1111/j.1467-9493.2008.00323.x.

Porter, Natalie. 2019. Viral Economies: Bird Flu Experiments in Vietnam. Chicago, IL: University of Chicago Press. 